\title{
Parenting and Education: The Example of Refugee Parents in Greece
}

\author{
GEORGIA SARIKOUDI AND ANNA APOSTOLIDOU
}

\section{Abstract}

This article focuses on the interplay between parenthood and refugee status and documents the approaches that parents employ to become educational agents and enrich their children's language knowledge and cultural capital while residing in refugee camps in northern Greece. It discusses the prominent role that encampment times play in structuring the disempowering refugee condition, and describes the parents'strategies of managing time and teaching their mother tongue and homeland culture to their children but also through becoming students themselves. In doing so, it highlights the accentuated parental role as a mediator between "home" and future residence and touches upon the repercussions of parents' involvement in their children's education. Based on anthropological fieldwork, this article highlights instances where the active parental role presents itself as a tactical means to counterbalance the reported loss of agency that the refugee positionality entails.

\section{Résumé}

Cet article porte sur l'interaction entre la parentalité et le statut de réfugié et documente les diverses voies employées par les parents afin de devenir des agents éducatifs et denrichir les connaissances linguistiques et le capital culturel de leurs enfants alors qu'ils vivent dans des camps de réfugiés dans le Nord de la Grèce. Il traite du rôle important que le temps passé dans les camps joue dans la structuration de la perte d'autonomie propre au statut de réfugié et décrit les stratégies de gestion du temps des parents, qui enseignent la langue maternelle et la culture du pays d'origine à leurs enfants, mais deviennent aussi eux-mêmes étudiants. Ce faisant, il souligne l'accentuation du rôle parental en tant que médiateur entre le pays d'origine et la future résidence et aborde les répercussions de l'implication des parents dans léducation de leurs enfants. S'appuyant sur une étude de terrain anthropologique, cet article présente cet article s'intéresse aux situations où le rôle parental actif apparaît comme un moyen tactique de contrebalancer la perte d'agentivité reportée qu'implique le positionnement de réfugié.

\section{Introduction}

ince the early 1990s, when the first migrants from East- ern European and Balkan countries arrived in Greece, $\checkmark$ the country has been transformed from a locale of emigration into a host country for persons of various ethnic and national backgrounds, which has had a significant effect on the political and cultural treatment of otherness

Cette œuvre en libre accès fait l'objet d'une licence Creative Commons Attribution-NonCommercial 4.0 International License, laquelle autorise l'utilisation, la reproduction et la distribution de l'œuvre sur tout support à des fins non commerciales, pourvu que l'auteur ou les auteurs originaux soient mentionnés et que la publication originale dans Refuge: revue canadienne sur les réfugiés soit citée. 
in the official discourse as well as everyday life. Intensified migration movements towards Europe and the "refugee crisis" during the last decade have been viewed as expressions of growing global interconnections. In the past few years, however, and increasingly after 2015, migratory flows dramatically changed. Until that point hundreds of thousands of asylum seekers had been crossing the geographical trail across Greek soil in order to continue their journey with the desire to be located in central and northern European countries. Following March 2015 and the closing of the "Balkan route," thousands of people from the Middle East, Asia, and Africa crossed the Aegean Sea to arrive on Greek islands in unsafe and undignified conditions, ${ }^{1}$ only to find the way to other European countries closed. The closing of the borders created a new understanding of spatiality in the European crossing, and, as it is ethnographically evident, dramatically shifted refugees' prior projects for settlement, occupation, and, consequently, education. Under the new conditions, several thousand people have remained trapped in hosting structures for several months or years at a time, while waiting for their cases to be examined. These structures, also known as camps (katavlismoi), were created under extreme political and social pressure and constitute spaces of emergency and exception, where the residents experience prolonged immobility and waiting, faced with material and psychosocial constraints.

During a critical time in the host country, which had been undergoing major economic and social turmoil, ${ }^{2}$ this pressing situation resulted in a reorientation of the priorities that state and private agents set for management of refugees in Greece, by intensifying and systematizing, among other things, the educational provisions available. This is partly due to the fact that a significant percentage of the newcomers were families with children: out of the approximately 46,000 refugees who currently reside in Greece, ${ }^{3}$ more than 20,000 are children, ${ }^{4}$ the educational care of whom became a firmly stated international priority. 5

As the Greek state had no previous experience in integrating refugee children into Greek public schools, international NGOS and volunteer organizations were the first ones to provide lessons for children in camps, which "served more to keep the children occupied than to provide them with a real education." ${ }^{\prime}$ It was not until March 2016 that the Greek government set up a scientific committee to organize the gradual integration of refugee children into the Greek public educational system. In 2017 the Ministry of Education created 145 reception classes across Greece. Children who lived in the camps were transferred daily into those afternoon reception classes under the supervision and financial support of the International Organization for Migration (IOM). ${ }^{7}$ However, this program had challenges to overcome: inexperienced teachers, lack of appropriate textbooks, conflicting schedules between school life and inter-camp educational activities, problems with children's ages and the decrease in their attendance rate, and suspicion or hostility from Greek local communities. In the camps that we visited, only 20 per cent of the children attended in-camp educational activities or afternoon classes in Greek public schools, with a high percentage dropping out.

The present article approaches the experience of forced migration on parents, and individuals who become parents, during displacement or entrapment in liminal spaces (such as camps) that affect the performance of their parenting roles. In doing so, it focuses on refugees' educational needs and expectations and on parents' involvement in their children's education, drawing on fieldwork research that took place in northern Greece during 2017. The discussion that follows is premised on certain empirical assumptions: the largest part of the population apprehends their situation as transitory, i.e., they hope and seek ways to relocate, usually rendering their local plans as temporary, so the population is very mobile; the majority is in a state of encampment, in conditions that fulfil the minimum requirements of a routine, normal, daily life for children and adults; they have limited access to material and technical resources; finally, their personal and family "educational projects" are being constantly reshaped under the pressure of other-more urgent, in their viewcontingencies regarding housing, employment, health, legal status, reunification, etc. ${ }^{8}$ In light of these observations, we examine the performance of parental roles and the potential they present for self-identification, management of cultural capital, and control over the concept of time in conditions of encampment.

First, we seek to explore the ways and degrees to which parents (or parenthood actors) engage with the education of the children they care for in these socio-political conditions; second, we point out the attitudes towards their own educational plans in relation to the refugee experience and their parenting role as agents and carriers of cultural capital trying to create spaces of routine and normality for themselves and for their children in this prolonged liminal situation. The central research questions that informed our ethnographic study can be summed up as follows: (1) What are the main conceptualizations and education-related practices of parents of refugee children? (2) What are their expectations of the educational provisions? (3) What are their main strategies to counterbalance the reported loss of agency they experience? In addressing these key questions it is worth noting that, despite the state's concern with the provision of formal education and schooling, the term education here is intended to include a wide array of learning practices (non-formal activities, remedial education, and family education) and the 
attitudes towards schooling as expressed in a non-formal context, thus contributing to wider approaches on the anthropology of education that adopts an elaborate definition of education that stretches beyond schooling or non-formal learning. ${ }^{9}$ After detailing the methodological orientation of the study and providing a context for the educational provisions in "transit" countries, our principal focus lies on accounting for parents' strategies of language learning and transmitting elements of their cultural heritage to the children, while trying to control the intricacies of encampment time, so as to minimize the sense of "time wasted." We discuss their conceptualizations as educational guardians and we present examples of performing culture and making tactical choices in order to ensure a balance between home countries and future aspirations of integration in the European context.

\section{Fieldwork Context and Methodology}

The ethnographic material that supports our findings was collected from October 2016 until May 2017 and was predominantly based on qualitative research: mainly participant observation, along with open informal discussions and semistructured interviews. The fieldwork research was carried out in two main camps of Thessaloniki-Diavata and Softex-in the industrial area in the west side of the city of Thessaloniki (within a twenty-five-kilometre radius) in northern Greece. Since 2015, Thessaloniki has been on the receiving end of many refugee and asylum-seekers waiting for relocation. The Diavata camp, which had been a military camp in the past, surrounded by walls and fences next to large areas of land and old factories, was the largest camp in the area of Thessaloniki at that time with 1,200 inhabitants, mostly Syrians and Afghans, and numerous local and international NGOS involved in the general management and the in-camp education provisions (language lessons, creative work, and sports activities). The Softex camp is in the facilities of an old paper factory, near the morgue and the city prison. Seven hundred people, mostly Syrians, were settled there at the time of our field research. Although this camp is the closest to the centre of Thessaloniki, there is no easy access to it. To reach this camp one requires a twenty-minute walk from the nearest bus stop through an isolated area, between abandoned factories and gas stations. In Softex only three NGOS were active and only one of them organized daily language lessons (Greek, Arabic, English) for children, or activities for adults (woodcarving, sports, language lessons). The fluidity that characterized life in camps was evident in the courses and the activities offered in both camps: most courses were attended erratically, educators were frequently changing, practising different methods and approaches, and NGOs were altering the courses and activities, based on interest, stability of attendance, and the learning profiles of attendees.
Following standard participant observation methods, and taking all standard ethical measures to ensure the confidentiality and safeguarding of our informants, we tried to have an almost daily presence in the selected camps and to create a network of informants. This proved to be a complex task, as the state agencies, NGOs, and refugee communities closely monitored and filtered our presence there. After having gained the consent of persons and organizations involved, we began attending some of their daily activities that led to frequent visits to refugees' tents or containers, which gradually led to in-depth conversations.

As team members of a larger multi-site research project on refugee education, ${ }^{10}$ we employed a methodological strategy that encompasses the needs of youth and adults of the refugee population, in keeping track with the other research sub-teams (located in Lesvos and Attica): we employed life histories, participant observation, semi-structured interviews, informal talks, in combination with child-centred methods and methods suitable for research in non-formal and informal educational settings, such as classroom interactions, assigned projects, drawings, and role play. We attended the improvised (self-made) schools that were created in both camps under the initiative of certain NGOs and with the supervision and guidance of the ministry's education coordinators.

Our main demographic focus was families with one or two parents residing in the refugee camps along with their children, as this presented the most interesting ethnographic material in the camps. We conducted ten semi-structured interviews, mostly with adults whose children attended the educational activities consistently, but the range of the people we regularly met and talked to consisted of thirtyone people (aged five to fifty-three) who came mainly from Syria, with only a few families from Afghanistan and Iraq. Communication was held in English, French, or Arabic with the help of a translator, and we were particularly cautious about identifying and addressing the power relations and hierarchies in the families or the classroom settings as they were expressed in the interactions between children, adults, parents, educators, and camp agents. Our interlocutors presented a wide variety of educational levels: we talked with people who were illiterate, those who had completed elementary school, and some who had a university diploma (teachers, mathematicians, mechanics, and nurses). As far as their residency status is concerned, the majority of the women had applied for reunification with their husbands who lived in other European countries (usually Germany, where they have been granted asylum), while others had asked for relocation or asylum in European countries, or in Greece. Most interviews and informal talks took place in the informants' tents, containers, or apartments, but we also 
accompanied them throughout their interactions with social services, in entertainment places, and in most of the educational activities they attended (language courses, excursions to museums and archaeological sites, etc.).

\section{Refugee Education in Transit}

Numerous studies highlight the importance of educational provision for refugees, especially in transit conditions, ${ }^{11}$ where they encounter obstacles ${ }^{12}$ that stretch from material barriers (lack of physical buildings) to administrative problems (inefficient curriculums, lack of teachers with appropriate training, and no accreditation for courses taught in camps) and other shortcomings. In transit countries such as Greece, studies about refugees focus on bureaucratic issues concerning the asylum process, ${ }^{13}$ prospects of their social integration, access to the economy, the prospect of constructing a new home, ${ }^{14}$ and the humanitarian responses towards the newcomers. ${ }^{15}$ Studies on refugee children's education in Greece are notably scarce, with the exceptions of Papataxiarchis, ${ }^{16}$ Daskalaki and Leivaditi, ${ }^{17}$ and Nagy (2018). ${ }^{18}$ Nagy presents a case study of a camp in the area of Perama, a neighbourhood in which the far-right party gained a high presence in the elections, on the interplay of crisis, hospitality, and solidarity. Papataxiachis, along with Daskalaki and Leivaditi, study the situation on the island of Lesvos; Papataxiarchis describes non-formal educational practices in hospitality structures, whereas Daskalaki and Leivaditi focus on the connections between education and in-shelter relationships with caretakers in an unaccompanied minors' shelter at the same location. Recently the work of Marmaridou ${ }^{19}$ and Mogli, Kalbeni, and Stergiou ${ }^{20}$ in the same location have focused on the role of the teacher in refugees' education in hosting structures. Marmaridou's research draws on two cities in northern Greece and describes the socio-emotional expressions of refugee children as experienced by their teachers and the practices that the latter employed to ensure a safe and welcoming environment for the children. On the other hand, the work of Mogli, Kalbeni, and Stergiou focuses on two big cities in central Greece and analyzes the problems caused in educational procedures by lack of training of teachers in reception facilities. As the authors demonstrate, lack of skills, lack of knowledge about refugee students' cultural beliefs and practices, difficulties in communication, and the state educational policy that focuses on the students' academic rather than social needs are the most crucial challenges facing teachers in their effort to approach and support refugee students educationally and emotionally. ${ }^{21}$ In the aforementioned studies, parental involvement is mentioned seldom, if at all. In practice, however, many parents have been active in treating systemic and practical deficiencies, as they regard education to be essential for their children.
The relevant literature links refugee parenthood and education, in terms of goal-setting for their young and adolescent children, ${ }^{22}$ or in terms of using their cultural background to gain access to (higher) education. ${ }^{23}$ Although the literature largely indicates how important refugee parents' involvement in schooling is, it mostly views parents in auxiliary roles and not as active agents who transmit knowledge and cultural understanding to the younger members of the family. Drawing from our fieldwork, we wish to offer sufficient data to demonstrate that parents have a decisive role in their children's education and seek to challenge the disempowering position of the refugee condition.

\section{Parenthood and the Refugee Condition}

Forced migration transforms the family system. The experience of war or violent conflict in the country of origin and the difficulties encountered when fleeing affect family structures as well as individual educational experiences and future plans. Prolonged stay in temporary refugee camps with malnutrition, illnesses, separation of family during flight, injuries, lack of education, and loss of tranquillity and stability are some of the issues that a family can experience before entering the new country, ${ }^{24}$ often resulting in radical reconfiguration of familial ties and drastically affecting the parental roles of people on the move. ${ }^{25}$

In many cases, when refugees enter a new social and culturally diverse environment they may be confronted with parenting styles and practices that are different from the ones they knew and upheld, causing them discomfort and awkwardness. ${ }^{26}$ Most of them have experienced trauma with consequences to their state of mind and affective attachments. ${ }^{27}$ Thus, refugees' adjustment to the new environment can evoke many challenges to parenting in the new society, ${ }^{28}$ which consequently affect their views, practices, and plans for their children's education. Research has indicated that perceptions about education before, during, and after the migratory experience are factors that define adaptation to the new cultural environment and constitute a considerable coping mechanism. ${ }^{29}$ Ethnographic approaches to parents or guardians/relatives as supporters of their children's goals and achievement indicate the personal and social significance that this role has for refugee parents of ethnic backgrounds (Bergnehr; Nagasa, both as cited in Merry et al., 2017)..$^{30}$

As far as integration and adjustment processes into the host country are concerned, parents are presented in the literature as notably slower than their children; they also face difficulties in assuming the figure of a role model for their children. They often find themselves turning to their children for help and guidance in the practical, cultural, and linguistic challenges in the new society. Furthermore, refugee parents are unfamiliar with the new school systems and need 
to cope with several constraints-linguistic, psychological, and practical-that hinder them from helping their children adapt in school life. Amira ${ }^{31}$ is a forty-three-year-old woman from Syria who lived for almost nine months in Softex with her two sons (five and eight years old) while her husband and her daughter have been granted asylum in Germany. Amira uses her elder son, Halil, as a translator when she goes to the open market or she speaks with the camp manager. Even though his level of Greek is not high (he is not capable of translating an official document), she feels more secure to have him with her. This role reversal, where children often take on the role of family spokesperson, ${ }^{32}$ is rather commonly observed in refugee and migration studies in recent research; however, parents experience further disempowerment when they depend upon their children for everyday communication and/or mediation with local people and services. In the following section, we wish to demonstrate that, given the limited material and immaterial resources of the refugee state, the management of encampment time is one of the few means that helps counterbalance this disempowering condition.

\section{Parenthood and Encampment "Time"}

Time in the refugee context, especially in prolonged periods of the "transit" condition, is extremely important in shaping everyday routines, establishing normalcy in family structures, and preserving individual well-being. The concept of time wasted and time lost is a recurring theme in the field notes collected from sites in Athens, Lesvos, and Thessaloniki in the context of Project PREss. 33 The time of encampment is perceived mainly as a time of waiting, a time controlled by others (camp routines, providers of goods, food, lessons, etc.), and often a time of rupture that includes the new cultural realities that define life in the new setting. The flourishing ethnographic literature on migration offers abundant proof of tensions between different forms of waiting, indicating that the experience of prolonged waiting may be seen as an imposed form of sanctioning used to slow movement towards Europe, for example, as a means to keep people out by making them linger and await decisions beyond their control. Such prolonged forms of waiting are reported to have a corrosive effect on many undocumented migrants, making their entire situation one of transience, with a grave effect on daily life. ${ }^{34}$ This enforced experience often results in a feeling of loss of agency in individuals' key roles and identities, such as the parental one. In other cases, it constitutes an opportunity to intensify and enrich the parental role. According to our observations, many parents demand active engagement in their children's education. ${ }^{35}$ Their request that their children's time not be wasted is also predominant in this example, echoing concern about the "lost generation" of pupils in the Syrian refugee crisis $^{36}$ but also indicating the importance of time in the transient refugee state.

Furthermore, this biopolitical component that runs through everyday manifestations of children and adult refugees defines the ways education is perceived as a normative component of family life and, consequently, a key factor that affects the decision to participate in education and under which terms. Parents' main demand is that their children enjoy a constant and continuous process of learning. Many of these children have lost several school years because of wars and expatriation; thus, parents hope their children can regain the school rhythm, a daily routine, 37 and school rituals that structure children's lives and help them to become integrated. A daily school program without interruptions and gaps would reassure them that their children are learning. The identity of a student, and also the chance to socialize and learn, are the top priorities expressed by parents in the field.

Therefore, education plays a double role, since it underlines the time-related parameter of everyday life but is also a cornerstone for the future development of the family. As Daskalaki, Tsioli, and Androulakis observe, ${ }^{38}$ strategies of families to ensure a better future often determine their choices (e.g., language learning, schooling, etc.), and the management of time by parental figures partially reinstates the fragmented time in the camp. Time entails both the reality and materiality of the present but also extends to the imagined future (usually placed in a different geographical place) and thus becomes even more precious in the encampment. As parents in the field publicly and individually expressed it, their role as managers and preservers of this precious currency is valorized as important, and it offers a means of individual agency, which may be coined in terms of responsibility, but also affection for children and family. Parents also worry that children have limited opportunities to communicate and mingle with non-refugee Greek children, which is a prerequisite for learning a language and becoming part of a society. "They don't feel like students. There is problem. They are alone. Why couldn't they play all together? Our children alone, Greek alone. They don't feel students, they feel alone. They do not play all together." Therefore, parents push for a daily schooling routine for their children, not only to acquire knowledge and reclaim time but also for continuous interaction among the children and between children and teachers. In their view, daily interaction is a major component that structures children's lives and helps them to become integrated.

\section{Parents as Educational Guardians}

This section discusses the attempts of numerous parents to follow their children's progress at school, even though few of 
them are familiar with the Greek language. Although most of them believed or hoped that their stay in Greece would be temporary, they regard schooling in transit conditions as a necessity and send their children to informal and formal schools inside and outside the camps. However, the school schedule for refugee children and their parents' expectations seldom coincide. Parents from the Softex camp called for two meetings with their children's teachers and expressed their concerns about the loosening of the school program. Among parents' many complaints to the educational coordinator of the Ministry of Education, they were concerned that their children were not learning anything of value and were wasting their time: "If he does not write with his hand, he will never learn." "No exercises for home. They have many 'gap' [empty] hours, instead of doing lessons. They are playing all the time and they don't make lesson. Inside the camp are learning more than the Greek school."

It is common for parents to criticize the way in which Greek language is taught to their children. Abbas, a thirtyfive-year-old Syrian man, who lived with his wife and their four children for almost a year in the Softex camp, offers: "In Syrian schools first we learn the letters and then slowly, slowly we learn to write. Here it is the opposite. If the children learn the letters, the basics, then they will learn to write correctly. You give them phrases for dictation, but they don't know what they write. If you teach them the alphabet and then you put them to write and write, they will learn more quick and they will get used to it."

Abbas and his family have asked for asylum in Greece, so they believe that learning the language is mandatory for their children. However, he and his wife don't attend Greek courses, using the excuse that they both work to make ends meet. They work for an international NGO in the camp for less money than they would earn somewhere else. They also hope that in working for an NGO they will meet the "right" people who can improve their stay in the camp, help their children with lessons, or make things easier for their asylum application. This is their way to establish and make use of a cultural capital that, according to their view, will promote their living situation in the camp.

Claiming a visible role in the camp and advocating for their children's education, many parents negotiate a new social position, a kind of "transit citizenship," which allows them to use their knowledge, assets, and attitudes to coformulate the education of their children. Ethnographic and intersectional accounts on how parenting can be conceived as a citizenship practice 39 point to the importance of practising parental care in education. ${ }^{40}$ Often mothers' new citizenship is fragile, as shown in the research findings on Kurdish refugee families, ${ }^{41}$ and the role of fatherhood is especially challenging in the refugee condition, as among
Sudanese refugees, ${ }^{42}$ whose values and cultural background guide their behaviour and choices as fathers. Abbas and the rest of the group of parents demand full participation of their children in schooling and the mainstream curriculum. They express their discontent for the slow pace of the courses offered to children in formal education, the inadequate homework, and the non-disciplinary approaches of the Greek educational system. In all those cases, the active engagement of parents in the education of their children, directly or indirectly, grants many of them the power that has been diminished or lost in the conditions of forced migration. 43 This strategy is not uncommon for persons who find themselves in a disadvantaged position when they are perceived as inferior.

At the same time, however, certain parents who send their children to formal school feel that they gain institutional security while in the encampment. "Softex is a dangerous camp, but we are good people. We go to work and my children go to school. My daughter everyday takes on her bag and waits outside of the container the school bus. When she sees it she runs towards it yelling, 'I'm going to school!' This is our effort to adjust." Abbas, like many other parents, claims that getting a child to school, which is one of the most powerful and normative mechanisms of the state, is a procedure in which the child learns the new culture but also ensures better living conditions in Greece and on some level grants the whole family a more secure status, if only discursive, through participation in institutionalized knowledge formation. As he believes, this is also an investment for the future; their narrative indicates that if their children learn Greek and adjust well to the Greek educational system and way of life, it would be easier for them to get asylum there. This coincides with what Fiddian-Qasmiyeh 44 terms "the politics of survival" in proposing that refugees often recognize the extent to which being perceived to be "ideal" refugees facilitates their life, as it attracts the attention and support of Western academics, NGOS, and civil society and solidarity networks.

It is also worth noting that in spite of the extremely disadvantaged living conditions, the precariousness and the dangers that prevail in the camps, many families have decided to remain in them and not to move to a flat-which the UN and NGOs provide-because they believe that would terminate their children's school attendance. This is a remarkable strategy, since it contests the general public discourse about the importance of material needs vis-à-vis educational needs. The decision not to opt for a more comfortable everyday living in pursuit of systematic attendance at school and schooling activities indicates that the priorities for longterm empowerment and improvement of the family position override present difficulties. 


\section{Parents as Students: Learning Languages}

For most of our field interlocutors, learning more languages than the mother tongue is an important asset. English and German are their top priorities and, even though Greek is not a common language, parents are glad that their children are learning it, because they see it as a tool that can considerably improve their residence in Greece. In this direction, some parents are eager to study Greek themselves in order to be able to help their children learn Greek. "English we can help our children, but Greek we cannot." Therefore, they try to find a way to somehow learn the language, so they can supervise their children and forge stronger bonds with the local culture.

Amira devotes most of her time and energy on the education of her children. To be able to help them, she finds time to attend language courses. Amira asked us if we could teach her the Greek language inside her container once a week, so that she will not spend more time away from the camp. She also occasionally attended English courses in the camp, and she goes to German lessons outside the camp. Although she presented herself as a "lazy student and an old mind who forgets things," she is quite diligent and she was almost impeccable when we checked her progress in the Greek language. As she told us a couple of times, "Learning is good. I don't want to let time pass by and only sit. I want to do things. It seems that her refugee experience is strongly influenced by language learning, since she learns three languages, and during most of her time she studies, goes to courses and activities, and takes care of her domestic duties.

However, language learning is also concurrent with each family's plans and aspirations. Mariam is a fifty-three-yearold English teacher from Syria who lived with her daughter and her husband for over a year in Thessaloniki. They have requested relocation to Germany, where her son lives with his family. With her children's encouragement, Mariam started learning German in order to make her time in Greece beneficial. Although she knows that NGOs organize language courses in the city centre, she chose online courses and in fact the very website her son recommended. He was the one who sent her a smartphone from Germany to motivate her. Although she is not particularly familiar with the use of the phone in general, and much less as a learning tool, under her son's instructions and with her daughter's assistance she uses it smoothly. Amira also teaches her two children English and German. "Whatever I learn in those courses, I want to pass it to my children. Every night for a couple of hours we do our own little homework. Alphabet in four languages (Arabic, Greek, English, and German) and some words and grammar. Little things. Even when we watch fairy tales on YouTube in Arabic, I ask them words in Greek and in English. Everything is a learning and teaching opportunity." They learn Greek to improve their present condition, German because they applied for family reunification there, and English because "it is the language that we can use in any country we will end up." For Amira, education is a way out of an "empty" everyday routine, an investment in the direction of a better future, but also a means of performing parenting outside the limited arena of her expected gender roles.

\section{Parents as Teachers: Performing Culture}

Closely related to the issue of foreign languages is the attitudes towards learning the mother tongue. Although parents complained about children's fatigue from all-day schooling, no one wanted the Arabic language lessons in the camp to stop. As most of them stated, children should learn their mother language "no matter what." "If they learn the mother tongue, then they can learn all the other languages, but the most important is to learn the mother tongue," according to Abbas. When asked why he doesn't teach his children Arabic so that they would not have to attend school both in the morning and in the afternoon, he said, "Arab teacher teaches grammar, words, and mathematics. I 'speak' [teach] them culture; to be good people, to respect the others." As he told us, he spends most nights singing and teaching his children to play the lute. "No one will teach them this part of our history. I want my children to learn the music traditions and practices and the habits of Syrian people. So I have to be this teacher and guide." For Abbas, school is responsible for educating his children, but he is the one who will instruct and form their Arabic culture. He employs notes, lyrics, and stories to induct them into their ancestral history. As he admits, it is not an easy task; children get bored easily and show no interest in his stories. To make his effort more effective and motivate his children, he included his mobile phone in his narration. He attracted their attention by showing them photos, videos, or documentaries about Arabic history and culture. "They spent most of their time on screen playing games and watching videos. Why not using this for learning purposes? In this way they pay more attention when I narrate stories, they get more fascinated," Abbas is an example, yet not unique. As Roer-Strier and Strier 45 show in their study of immigrant families in Israel, parents for whom cultural traditions are important and who try to teach those traditions to their children find themselves in conflict with the educational system of the host country. Resolution of this tendency often comes by merging the two contrasting worlds through the children's education (even if systematic home-schooling is not the norm for most). As bearers of a place and culture mostly occupied by the performance of memory, many refugee women and men maintain their 
parental agency as transmitters of the language, oral tradition, and sensory imprints of the home country, differentiating themselves from the role of the formal teacher, yet maintaining a strong pedagogical and shaping influence in the lives of their children.

Along similar lines, Mustafa, a forty-three-year-old taxi driver from Syria, admitted that he was very concerned about his daughters' ethical guidance. His wife and their three children lived in Diavata for over a year. He managed to reach Germany and lived there for seven months, when he was granted asylum and then he returned to Greece and secretly lived in the container with his family. As he said, he preferred to go back and forth rather than leave them unattended. Although his wife was a teacher in Syria and taught Arabic in the informal school in Diavata for some time, he was the one teaching them their tradition and religion through songs, customs, and history movies. "I am not only teaching them the language, but also our culture." Although he was very persistent in sending their daughters to school, he was very cautious about the fact that in the Greek school boys and girls are in the same classroom and interact with each other. He even considered going back to Syria so that his children would have the "proper" upbringing.

As our fieldwork data indicate, the high valorization of the teacher figure is intrinsic to most refugees' cultural understanding of education. Thus the performance of the parental role as a teacher in the cultivation and preservation of cultural elements (mother tongue, music, cooking, etc.) within the family combines two highly important cultural components: family and education. In employing Bourdieu's view, ${ }^{46}$ we discern how transmitting the habitual and embodied state of one's cultural capital (through recreation, caretaking, and communication of values) is utilized to make up for the loss of the objectified and the institutionalized state of capital compromised by the encampment condition. In being unable(d) to occupy a recognizable citizenship role, to be systemically excluded from formal education and linguistically estranged from local daily activity, many refugee parents make up for this loss in agency by attaining a stronger "instructional" position in their children's lives and turn the preservation of their cultural capital into a central parental concern. This emphasis on cultural capital builds on the long anthropological discussion about shifting understandings of territorialization, and how (home)lands that can no longer be corporeally inhabited become strong imagined landmarks for moving populations. 47

\section{Closing Remarks}

Refugee parents' thoughts and practices highlight their active engagement with their children's education, despite obstacles that the encampment condition poses in the performance of parental roles. Although they faced challenges, including the lack of Greek language, and cultural and material resources, parents developed strategies to overcome them, to organize the disordered daily life in the camps, and to become educational caretakers and agents for their children. Learning the language and transmitting the cultural heritage to their children are principal goals of many parents in the camps of northern Greece. Many parents learn the language of the host country in order to be able to assist their children, while following their children's progress and demand from teachers a less "loose" program in order to eliminate the sense of "time wasted." Others attain a teaching role in transmitting cultural knowledge and preventing their children's assimilation. In their effort to assure a better future for them in Greece or in a future destination country, parents adopt educational and mediating roles that grant them a greater sense of control over their families' present and future being. As we have ethnographically demonstrated, their efforts to appropriate time, cultural knowledge, and parental agency might give them back some of the power that they lost while traversing the processes of forced migration and encampment.

\section{Notes}

1 E. Papataxiarchis, "Being 'There': At the Front Line of the 'European Refugee Crisis'-Part One," Anthropology Today 32, no. 2 (2016): 5-9; Papataxiarchis, "Being 'There': At the Front Line of the 'European Refugee Crisis'-Part Two," Anthropology Today 32, no. 3 (2016): 3-7.

2 G. Agelopoulos, "To Whom Are the Greeks Bearing Gifts? Aspects of the Refugee Crisis in Greece," Irish Journal of Anthropology 18, no. 2 (2015): 9-12.

3 See https://data2.unhcr.org/es/documents/download/60528.

4 See UnHCR, "Refugee and Migrant Children in Europe: Accompanied, Unaccompanied and Separated," June 2017, https://data2.unhcr.org/en/documents/download/58431.

5 According to UNHCR reports and estimations, more than half of all refugees are children of school age; thus international organizations, governments, and NGOS focus on the education and schooling of these children as fundamental for their integration in the new place, as important as shelter, nourishment, and sanity. See Y. Rah, S. Choi, and T.S.T. Nguyễn, "Building Bridges between Refugee Parents and Schools," International Journal of Leadership in Education 12, no. 4 (2009): 347-65. See also Scientific Committee for the Support of Refugee Children (Ministry of Education, Research and Religious Affairs), "The Project of the Education of Refugees," April 2017 (in Greek).

6 S. Nagy, "From Camps to Schools: The Participation of Refugee Children in Greek Public Education," Journal of Modern Greek Studies 36, no. 2 (2018): 385. 
7 G. Simopoulos and A. Alexandridis, "Refugee Education in Greece: Integration or Segregation?", Forced Migration Review 60 (2019): 27-9.

8 I. Daskalaki, S. Tsioli, and G. Androulakis, "Project PREss: Ethnographic Approaches to Refugee Education in Greece," in Proceedings of the 9th International Conference on Open and Distance Learning "Education Design," November 23-6, 2017 , ed. A. Lionakis, S. Ioakeimidou, M. Niari, G. Manousou, T. Hartofylaka, S. Papadimitriou, and A. Apostolidou, 23-6 (Athens: Hellenic Open University, 2017), (in Greek).

9 K.M. Anderson-Levitt, "Intro: Anthropologies and Ethnographies of Education Worldwide," in Anthropologies of Education, ed. K.M. Anderson-Levitt, 1-28 (New York: Berghahn, 2013).

10 The Provision of Refugee Education and Support Scheme (PRESS) was a research-based project, funded by the Hellenic Open University, that aimed to help refugees' educational support and long-term educational empowerment. By bringing together social anthropology and sociolinguistics, the project aimed to produce ethnographic insights into the educational, linguistic, and communication priorities and expectations of refugee children, youths, and adults in Greece in order to furnish educational activities and integration. The duration of the project, which consisted of twenty-four distinct actions, was nineteen months (June 2016 to December 2017). Academic director, Professor George Androulakis; project coordinators, Anna Apostolidou, Ivi Daskalaki, and Sofia Tsioli. For more information, see Project Press, "Press Toolkit," http://press-project. eap.gr/toolkit/.

11 S. Dryden-Peterson, The Educational Experiences of Refugee Children in Countries of First Asylum (Washington, DC: Migration Policy Institute, 2015); Dryden-Peterson, "Refugee Education: Education for an Unknowable Future," Curriculum Inquiry 47, no. 1 (2017): 14-24; R. Hoss, "Education in Emergencies: Case of a Community School for Syrian Refugees," European Journal of Educational Research 5, no. 2 (2016): 53-60.

12 G. Lăzăroiu, "The Educational Status of Refugee Youth from Syria," Educational Philosophy and Theory 47, no. 13-14 (2015): 1383-4.

13 H. Cabot, On the Doorstep of Europe: Asylum and Citizenship in Greece (Philadelphia: University of Pennsylvania Press, 2014).

14 E. Arvanitis and N. Yelland, "Home Means Everything to Me': A Study of Young Syrian Refugees' Narratives Constructing Home in Greece," Journal of Refugee Studies, (2019), https://doi.org/10.1093/jrs/fezo3o; N. Kourachanis, "From Camps to Social Integration? Social Housing Interventions for Asylum Seekers in Greece," International Journal of Sociology and Social Policy 39, no. 3-4 (2018): 221-34.

15 Papataxiarchis, "Being 'There," parts one and two; K. Rozakou, "Solidarians in the Land of Xenios Zeus: Migrant Deportability and the Radicalisation of Solidarity," in Critical Times in Greece: Anthropological Engagements with the
Crisis, ed. D. Dalakoglou and G. Agelopoulos, 188-201 (London: Routledge, 2018); S. Chtouris and M.S. DeMond, "Refugee Flows and Volunteers in the Current Humanitarian Crisis in Greece," Journal of Applied Security Research 12, no. 1 (2017): 61-77.

16 E. Papataxiarchis, "Cohabitation Exercises in the 'Humanitarian City': Informal Educational Practices and Refugee Governance post-2016," Synchrona Themata 137 (2017): 74-89 (in Greek).

17 I. Daskalaki and N. Leivaditi, "Education and 'Hospitality' in Liminal Locations for Unaccompanied Refugee Youths in Lesvos," Migration and Society 1 (2018): 51-65.

18 S. Nagy, "From Camps to Schools: The Participation of Refugee Children in Greek Public Education," Journal of Modern Greek Studies 36, no. 2 (2018): 373-99.

19 M. Marmaridou, "Education of Refugee Children in Greece: Teacher's Experiences” (master's thesis, University of Jyväskylä, 2019), https://jyx.jyu.fi/bitstream/handle/ $123456789 / 66792 / 1 /$ U R N \% 3 A N B N \% 3 A fi \% 3 Ajyu 201912135265.pdf.

20 M. Mogli, S. Kalbeni, and L. Stergiou, “The Teacher Is Not a Magician': Teacher Training in Greece Reception Facilities for Refugee Education," International e-Journal of Educational Studies 4, no. 7 (2020): 42-55.

21 Mogli, Kalbeni, and Stergiou, "The Teacher Is Not a Magician," $52-3$.

22 J.M. Felter, as cited in L. Merry, S. Pelaez, and N. Edwards, "Refugees, Asylum-Seekers, and Undocumented Migrants and the Experience of Parenthood: A Synthesis of the Qualitative Literature," Globalization and Health 13, no. 75 (2017): 9.

23 A.D. Medina, as cited in Merry, Pelaez, and Edwards, "Refugees, Asylum-Seekers, and Undocumented Migrants," 10.

24 L.D. Adams and A. Kirova, "Introduction: Global Migration and Education: School, Children and Families", in Global Migration and Education: School, Children and Families, ed. L.D. Adams and A. Kirova, 1-12 (London: Routledge, 2006); E.H. Boyle and A. Ali, "Culture, Structure, and the Refugee Experience in Somali Immigrant Family Transformation," International Migration 48, no. 1 (2010), 47-79.

25 C. Suárez-Orozco and M. Suárez-Orozco, "Transnationalism of the Heart: Familyhood across Borders," in What Is Parenthood? Contemporary Debates about the Family, ed. L. McClain and D. Cere, 279-98. New York: New York University Press, 2013).

26 A.M. Renzaho and S. Vignjevic, as cited in Merry, Pelaez, and Edwards, "Refugees, Asylum-Seekers, and Undocumented Migrants," 6.

27 L. De Haene, as cited in Merry, Pelaez, and Edwards, "Refugees, Asylum-Seekers, and Undocumented Migrants," 7.

28 S.A. Deng and J. Marlowe, "Refugee Resettlement and Parenting in a Different Context," Journal of Immigrant \& Refugee Studies 11, no. 4 (2013): 416-30. 
29 R. Ramsden and A. Taket, as cited in Merry, Pelaez, and Edwards, "Refugees, Asylum-Seekers, and Undocumented Migrants," 5-6, 9.

30 D. Bergnehr and K.A. Nagasa, both as cited in Merry, Pelaez, and Edwards, "Refugees, Asylum-Seekers, and Undocumented Migrants," 15 and 16.

31 All the names used here are pseudonyms.

32 J.L. McBrien, "Educational Needs and Barriers for Refugee Students in the United States: A Review of the Literature," Review of Educational Research 75, no. 3 (2005): 329-64.

33 Daskalaki, Tsioli, and Androulakis, "Project PREss."

34 A. Bandak and M.K. Janeja, "Introduction: Worth the Wait," in Ethnographies of Waiting: Doubt, Hope and Uncertainty, ed. A. Bandak and M.K. Janeja, 1-39. London: Bloomsbury Academic.

35 Some of them pursue linguistic and cultural mediation during in-school and extracurricular activities, as is the case of mothers in the camp of Konitsa (in Epirus), who formed an informal coalition with educators and camp managers to assist the better integration of children in elementary school as well as schooling-like practices.

36 S. Deane, "Syria’s Lost Generation: Refugee Education Provision and Societal Security in an Ongoing Conflict Emergency," IDs Bulletin 47, no. 3 (2016): 35-52.

37 L. De Wal Pastoor, "The Mediational Role of Schools in Supporting Psychosocial Transitions among Unaccompanied Young Refugees upon Resettlement in Norway," International Journal of Educational Development 41, no. 3 (2015): 245-54.

38 Daskalaki, Tsioli, and Androulakis, "Project PREss."

39 C. Longman, K. De Graeve, and T. Brouckaert, as cited in Merry, Pelaez, and Edwards, "Refugees, Asylum-Seekers, and Undocumented Migrants," 15.

40 For an overview of the parenting experience of refugees, asylum-seekers, and undocumented migrants see also Merry, Pelaez, and Edwards, "Refugees, Asylum-Seekers and Undocumented Migrants."
41 U. Erel, as cited in Merry, Pelaez, and Edwards, "Refugees, Asylum-Seekers and Undocumented Migrants," 5-6, 15.

42 D.C. Este and A.A. Tachble, "The Perceptions and Experiences of Russian Immigrant and Sudanese Refugee Men as Fathers in an Urban Center in Canada," Annals of the American Academy of Political and Social Science, 624, no. 1 (2009): 139-155.

43 M.L. Van Korlaar, as cited in Merry, Pelaez, and Edwards, "Refugees, Asylum-Seekers and Undocumented Migrants," 9-10.

44 E. Fiddian-Qasmiyeh, The Ideal Refugees: Gender, Islam, and the Sahrawi Politics of Survival (New York: Syracuse University Press, 2014).

45 D. Roer-Strier and R. Strier, "The Role of Home and School in the Socialization of Immigrant Children in Israel: Father's Views," in Global Migration and Education: School, Children and Families, ed. L.D. Adams and A. Kirova, 10319 (London: Routledge, 2006).

46 P. Bourdieu, "The Forms of Capital," in Handbook of Theory and Research for the Sociology of Education, ed. J. Richardson, 241-58 (New York: Greenwood, 1986).

47 L. Malkki, "National Geographic: The Rooting of Peoples and the Territorialization of National Identity among Scholars and Refugees, Cultural Anthropology 7, no. 1 (1992): 24-44.

Georgia Sarikoudi is a post-doctoral fellow in Aristotle University of Thessaloniki. She can be reached at gsarikoudi@gmail .com.

Anna Apostolidou is a post-doctoral fellow and adjunct lecturer at Panteion University of Social and Political Sciences. She can be reached at anna.apostolidou@panteion.gr. 